\title{
EFFECTIVE AEROSOL TREATMENT OF MOULD MITES AND ONION THRIPS IN TISSUE CULTURE
}

\author{
C.W. VAN EPENHUIJSEN and J.P. KOOLAARD \\ Crop \& Food Research, Private Bag 11600, Palmerston North, New Zealand \\ Corresponding author: vanepenhuijsenk@crop.cri.nz
}

\begin{abstract}
Ethyl formate applied as an aerosol killed almost $100 \%$ of the mould mites (Tyrophagus putrescentiae) present in tissue culture tubs. Mite mortality showed dose responses to the chemical and mortality increased with duration of exposure. Other aerosol formulations, and vacuum and controlled atmosphere treatments were also tested but were not effective in controlling mites. Onion thrips (Thrips tabaci) in open and closed tissue culture tubs were killed by ethyl formate, $65 \%$ and $85 \% \mathrm{CO}_{2}$ atmospheres, or dichlorvos plus $\mathrm{CO}_{2}$ propellant. Further work is needed to define effective dose rates and exposure times and to determine the possible phytotoxicity of the aerosols to various plant species.

Keywords: fumigation, Tyrophagus putrescentiae, Thrips tabaci, tissue culture.
\end{abstract}

\section{INTRODUCTION}

Contamination of tissue cultures during micropropagation of plants is often the result of fungal infections introduced by mites and insects. Mould mites are more likely to be found inside tissue culture tubs containing agar than in temperature-controlled tissue culture rooms as the relative humidity in these rooms is much lower than the $\mathrm{RH}$ of $70 \%$ and higher favoured by the mites. Control of mites and thrips in tissue culture laboratories tends to be based on information shared informally between laboratories rather than on published information. Various control measures for mites and thrips are available but many are unsuitable for application to tissue culture material.

The fumigant, phosphine, is used to control mites in stored grain (Anon. 2003). However, it requires specialist application and cannot feasibly be applied in tissue culture laboratories because it is highly toxic (Blake 1988) and application vessels must remain sealed for 7 days. Furthermore, mite eggs may survive fumigation with phosphine.

Aerosol fly sprays containing pyrethrum insecticide have been recommended for use in tissue culture (Kirk 1997). CABI Bioscience (2002) recommends use of $70 \%$ ethanol on work surfaces and incubators to avoid mite infestations, and treatment of infested tissue culture tubs using a microwave was found to kill mould mites (van Epenhuijsen \& Koolaard 2004).

This paper describes a series of experiments aimed at developing effective controls for mould mite (Tyrophagus putrescentiae) and onion thrips (Thrips tabaci), which are two of the most common invaders in tissue culture laboratories in New Zealand. Control measures tested included aerosol formulations, elevated $\mathrm{CO}_{2}$ and vacuum atmospheres. One of the aerosols included ethyl formate, the active ingredient in VAPORMATE ${ }^{\mathrm{TM}}$, which occurs naturally in a range of products such as vegetables, stored grains, animal products, and beer and wine (Desmarchelier 1999).

\section{Rearing mites and thrips}

\section{MATERIALS AND METHODS}

A mould mite culture was started using mites collected from contaminated tubs of tissue-cultured calla plantlets. The mites were reared on a 50:50 mix of yeast and rat food (van Epenhuijsen \& Koolaard 2004). 
Onion thrips were collected from onions and reared in $500 \mathrm{ml}$ jars at $70 \% \mathrm{RH}$ at $27^{\circ} \mathrm{C}$. The lid of each jar contained filter paper for aeration; a piece of paper towel was placed in the bottom of the jars. Twice a week, pieces of leek (Allium porrum) leaves were added. Adult thrips for experiments were collected using a device designed to collect small insects (van Epenhuijsen 1995). For the treatments, 15 thrips were placed in $35 \mathrm{ml}$ jars with very fine mesh covering $18 \mathrm{~mm}$ vents at both ends of the jars. A small piece of leek was added to each jar. The jars were placed directly into the tissue culture tubs.

All the treatments in each experiment were replicated four times by carrying out runs on four different days. All treatments were applied at $22^{\circ} \mathrm{C}$.

\section{Aerosols, vacuums and controlled atmospheres}

A series of experiments examined the effects of aerosol formulations, elevated $\mathrm{CO}_{2}$ levels and vacuum atmospheres on mite and thrips survival in infested tissue culture tubs sealed with lids. For comparison, a second set of tubs without lids (open tubs) was also used. For each fumigation, four tubs were placed inside the fumigation chamber; two tubs (one open, one closed) contained mites, and two (one open, one closed) contained thrips. Wide-mouthed, plastic tissue culture tubs (290 ml capacity) with snap-on lids, commonly used for tissue culture in New Zealand, were used for the experiments.

Mould-mite infested diet ( $4 \mathrm{~g})$ was spread over the bottom of open and closed tubs without agar. After treatment, the infested diet was stirred with a needle and poured through a kitchen sieve (approximately $850 \mu \mathrm{m}$ mesh). The sieved material (a fine dust) was stuck on $50 \mathrm{~mm}$ wide black polyethylene self-adhesive tape (Sealed Air Insultape) by laying a piece of tape on the sieved material and rolling metal a piece of pipe over it. All live mites within in two randomly chosen $7 \mathrm{~mm}$ diameter circles $\left(77 \mathrm{~mm}^{2}\right)$ cut out of a thin aluminium sheet overlay were counted on the tape per treatment. Live mites, and dead and live thrips, were counted $2 \mathrm{~h}$ after treatment.

Aerosols. The treatments were:

- Aerosol 1: ethyl formate, (16.7\% ethyl formate: VAPORMATE $\left.{ }^{\mathrm{TM}}\right)$ in a liquid carbon non-flammable formulation, which formed a vapour.

- Aerosol 2: dichlorvos, (50 g/kg: Insectigas) with carbon dioxide as the propellant, which formed a vapour.

- Aerosol 3: permethrin+pyrethrum+piperonyl butoxide with carbon dioxide as a propellant $(4.0+1.0+5.0 \mathrm{~g} / \mathrm{kg}$ : Permigas $)$.

- Aerosol 4: EVI-500, pyrethrins + piperonyl butoxide: with dill added.

- Aerosol 5: tetramethrin + allethrin + d.phenothrin $(2.35+0.53+0.53 \mathrm{~g} / \mathrm{l}$ : Raid Fly \& Insect killer) with hydrocarbon as a propellant, was applied as a 3 second spray.

- Control. For each run of the trial, untreated tubs containing mites or thrips were kept at ambient temperature in the laboratory.

Aerosol 1 and 5 treatments were applied to a 92-litre (389 x 608 x $393 \mathrm{~mm})$ stainless steel chamber. The lid on the chamber was placed on high-density sponge rubber (Skellerup EPDM, $25.4 \times 12.7 \mathrm{~mm}$ ) cut into a rectangular shape to seat the lid. The lid was tightly fastened down during fumigation using two elasticised tie-downs. A handgun was used to introduce the gas through an $8 \mathrm{~mm}$ diameter port in the side of the chamber. The amount of gas introduced to each chamber was calculated by weight loss in the gas cylinder, which was placed on a scale. Aerosol 5 was applied from canisters (534 ml) purchased from retail stores. Aerosols 2, 3 and 4 were applied to jars placed on the floor of a sealed, lined enclosure $\left(30 \mathrm{~m}^{3}\right)$.

Vacuum treatments. Vacuum treatments were carried out in a $3.83 \mathrm{~m}^{3}$ tank under $9.63 \mathrm{kPa}$ and $2 \%$ oxygen, with the balance being Aerosol 2, Aerosol 1 or air (control). Assessments of mites and thrips were carried out 1-2 h after treatment.

Controlled atmospheres. In the controlled atmosphere experiment, $70 \mathrm{ml}$ jars containing mites were placed in open or closed plastic tissue culture tubs without agar in plastic sealable containers $(240 \times 180 \mathrm{~mm})$ containing wetted capillary matting to maintain high humidity. A plastic hose for the supply of $\mathrm{CO}_{2}$ was inserted in each container through a rubber bung. Two syringe needles acted as vents. Carbon dioxide (100\%) was delivered from pressurised cylinders (BOC Gases, Palmerston North) and mixed with 
air supplied via a compressor to give $65 \%$ or $85 \% \mathrm{CO}_{2}$ atmospheres. Treatments were applied for $24 \mathrm{~h}$. The gas mix was regulated to supply a constant stream of $300 \mathrm{ml} / \mathrm{min}$ to the containers. Regular checks of $\mathrm{CO}_{2}$ levels were made using a Dansensor $\mathrm{O}_{2} / \mathrm{CO}_{2}$ gas sensor. The chambers were kept closed for $2 \mathrm{~h}$ after the treatment. The untreated control consisted of air supplied to a plastic container. The set of treatments was replicated four times on different days.

\section{Ethyl formate treatments}

\section{Rates and exposure trial}

A trial was conducted to determine suitable exposure times and rates of ethyl formate to use in future trials.

Jars $(70 \mathrm{ml})$ containing mites were open during fumigation. Each jar contained $10 \mathrm{~g}$ mite-infested diet (approximately $8 \mathrm{~mm}$ deep) with a 30 × $30 \mathrm{~mm}$ piece of black filter paper (Schleicher \& Schuell) on the bottom. The jars were placed in 40 litre plastic bags. An appropriate quantity of ethyl formate (Merck-Schuchardt, Hohenbrunn), matching the rates deliverable by Aerosol 1, was poured into a glass Petri dish and also placed in the plastic bag, which was then sealed with tape. Bags were fumigated with 0 , $2,4,6,8,10,20$ or $40 \mathrm{~g} / \mathrm{m}^{3}$ ethyl formate. An air stream was introduced into the bag through a septum over the Petri dish to completely vaporise the ethyl formate and fill the bag. Bags were held at $20^{\circ} \mathrm{C}$ for 2,4 and $6 \mathrm{~h}$. Assessments were carried out after $24 \mathrm{~h}$ by counting all live mites in four randomly chosen circles (diameter $7 \mathrm{~mm}$ ) of the filter paper.

\section{Efficacy of Aerosol 1 in tissue culture tubs}

Open tissue culture tubs without agar and closed tubs with agar were fumigated in 200 litre drums at approximately $20^{\circ} \mathrm{C}$. The rates of ethyl formate used were $0,10,20$ and $40 \mathrm{~g} / \mathrm{m}^{3}$. Mite-infested diet $(1.5 \mathrm{~g})$ was spread over the bottom of the open tubs and $3 \mathrm{~g}$ of diet was spread over the agar in the closed tubs. In addition, begonia plantlets in tissue culture tubs containing agar were added to the 20 or $40 \mathrm{~g} / \mathrm{m}^{3}$ treatments or left untreated for phytotoxicity assessment.

The diet in the closed tubs could not be assessed because it became wet after absorbing moisture from the agar. All mites on the inner side of the lids on the closed tubs were counted. For the open tubs, live mites in 12 disk areas (each $38 \mathrm{~mm}^{2}$ ) of diet were counted. The assessments were carried out $24 \mathrm{~h}$ after treatment.

\section{RESULTS}

\section{Aerosols, vacuums and controlled atmospheres}

All the treatments, both in open and closed tubs, failed to suppress mite numbers, apart from the non-vacuum Aerosol 1 treatment, which had almost no surviving mites in the open tubs. This treatment gave only a moderate reduction of mites in the closed tubs. (Table 1).

\section{Thrips}

For the open tubs, Aerosol 1, Aerosol 2 vacuum, Aerosol 1 vacuum and $65 \% \mathrm{CO}_{2} /$ $35 \%$ air all gave $100 \%$ thrips mortality, while $85 \% \mathrm{CO}_{2} / 15 \%$ air gave $98.5 \%$ mortality (Table 2). The same five treatments that gave high mortality in the open tubs gave $100 \%$ mortality in the closed tubs. Aerosol 2 had some effect on the thrips in the open tubs but it did not penetrate into the closed tubs sufficiently to give any mortality. The other treatments were ineffective against thrips in either open or closed tubs (Table 2).

\section{Ethyl formate treatments \\ Rates and exposure trial}

When ethyl formate was applied to infested jars, numbers of live mites decreased with exposure time, but there was evidence of a greater rate of decrease in mite numbers in response to increasing ethyl formate dose (Fig. 1). At exposure times of 2 and $4 \mathrm{~h}, 40$ $\mathrm{g} / \mathrm{m}^{3}$ ethyl formate was required to reduce mite numbers. A statistically significant $(\mathrm{P}<0.05)$ reduction in mite numbers was seen at $20 \mathrm{~g} / \mathrm{m}^{3}$ with an exposure time of $6 \mathrm{~h}$. 
TABLE 1: Mean numbers of surviving mites (no. mites/77 $\mathrm{mm}^{2}$ ) in open and closed tissue culture tubs after treatment with various aerosols and controlled atmospheres.

\begin{tabular}{|c|c|c|c|}
\hline Treatment & Open tubs & & Closed tubs \\
\hline \multicolumn{4}{|l|}{ Aerosols } \\
\hline Aerosol 1 & 1 & & 76 \\
\hline Aerosol 2 & 224 & & 222 \\
\hline Aerosol 3 & 191 & & 211 \\
\hline Aerosol 4 & 211 & & 225 \\
\hline Aerosol 5 & 297 & & 252 \\
\hline Control (aerosols) & & 213 & \\
\hline \multicolumn{4}{|l|}{ Vacuum } \\
\hline Aerosol 2 vacuum & 235 & & 234 \\
\hline Aerosol 1 vacuum & 223 & & 262 \\
\hline Control (vacuum) & & 255 & \\
\hline \multicolumn{4}{|l|}{ Controlled atmosphere } \\
\hline $65 \% \mathrm{CO}_{2}, 35 \%$ air & 185 & & 202 \\
\hline $85 \% \mathrm{CO}_{2}, 15 \%$ air & 145 & & 228 \\
\hline Control (air only) & & 253 & \\
\hline $\mathrm{SEM}^{1}$ & 35.9 & & 40.1 \\
\hline
\end{tabular}

${ }^{1}$ Standard error of a treatment mean (pooled over all treatments) calculated from four replicate measures for each treatment. Aerosol 1 was excluded from this calculation since its counts were almost all zero.

TABLE 2: Mean proportion (with SE where appropriate) of onion thrips killed in open and closed tissue culture tubs treated with various fumigation, aerosol or controlled atmosphere treatments.

\begin{tabular}{|c|c|c|c|}
\hline Treatment & Rate $\left(\mathrm{g} / \mathrm{m}^{3}\right)$ & Open tubs & Closed tubs \\
\hline \multicolumn{4}{|l|}{ Aerosols } \\
\hline Aerosol 1 & 20 & 100 & 100 \\
\hline Aerosol 2 & 9 & $50.0(6.0)^{1}$ & 0 \\
\hline Aerosol 3 & 8 & $3.4(2.4)$ & $3.8(2.5)$ \\
\hline Aerosol 4 & 9 & $1.7(1.7)$ & $3.6(2.5)$ \\
\hline Aerosol 5 & 27.2 & $7.8(3.8)$ & $1.8(1.7)$ \\
\hline Control (aerosols) & & \multicolumn{2}{|c|}{$1.5(1.5)$} \\
\hline \multicolumn{4}{|l|}{ Vacuum } \\
\hline Aerosol 2 vacuum & & 100 & 100 \\
\hline Aerosol 1 vacuum & & 100 & 100 \\
\hline Control (vacuum) & & \multicolumn{2}{|c|}{$1.6(1.6)$} \\
\hline \multicolumn{4}{|c|}{ Controlled atmosphere } \\
\hline $65 \% \mathrm{CO}_{2}, 35 \%$ air & & 100 & 100 \\
\hline $85 \% \mathrm{CO}_{2}, 15 \%$ air & & $98.4(1.5)$ & 100 \\
\hline Control (air only) & & \multicolumn{2}{|c|}{$1.8(1.8)$} \\
\hline
\end{tabular}

${ }^{1}$ Data in parentheses are SEM. 


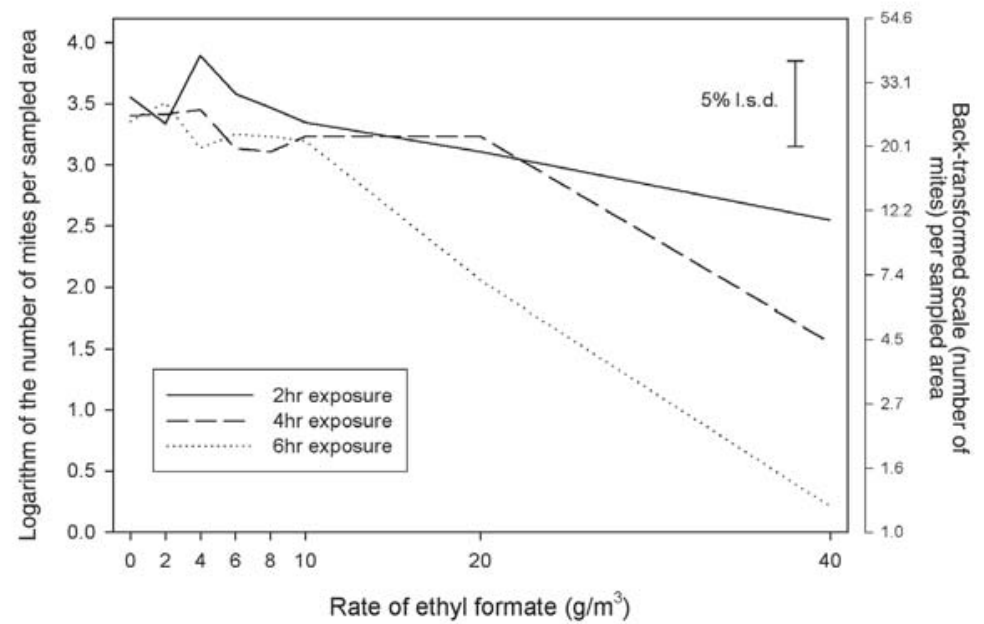

FIGURE 1: Number of mites found in jars after exposure to ethyl formate at various rates and durations.

\section{Efficacy of Aerosol 1 in tissue culture tubs}

Aerosol 1 applied to open tubs resulted in fewer mites $(\mathrm{P}<0.05)$ on average than the nil dose rates for all of the four rates tested (Fig. 2$)$. There was no difference $(\mathrm{P}<0.05)$ in mite numbers between the four rates of Aerosol 1 used.

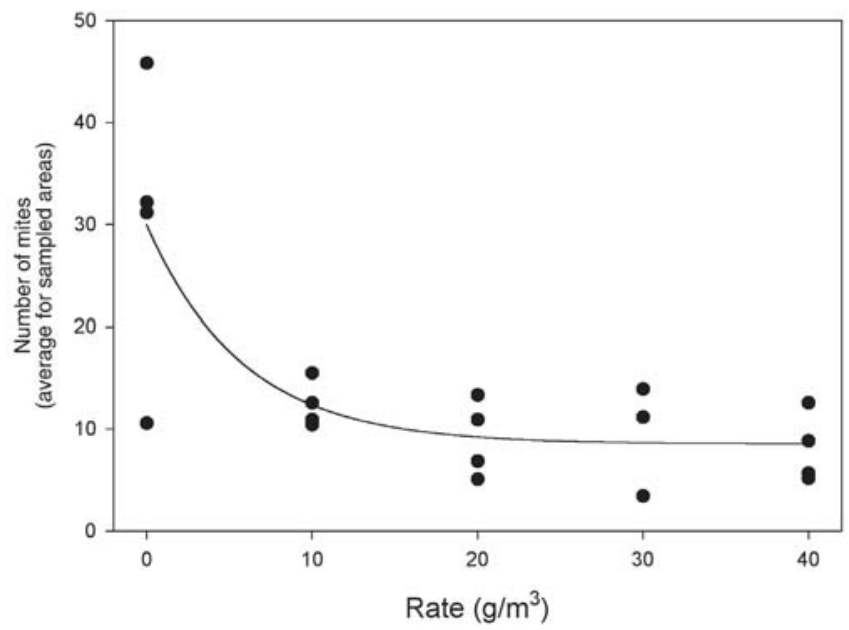

FIGURE 2: Numbers of mites in open tissue culture tubs after treatment with different ratios of ethyl formate. The fitted line is Number of mites = $8.5+21.42\left(0.84^{\text {Rate }}\right)$, and the standard error of observations about the fitted line is estimated to be 7.03 . 
Diet placed directly on agar in the closed tubs became wet and so live mites could only be counted on the inside of the lids. As with the open tubs, mite numbers in closed tubs decreased with increasing rates of Aerosol 1 . Rates of 30 and $40 \mathrm{~g} / \mathrm{m}^{3}$ halved mite numbers compared to the nil rate (Fig. 3).

No phytotoxicity was seen on begonia plants treated with Aerosol 1 at rates of 20 and $40 \mathrm{~g} / \mathrm{m}^{3}$.

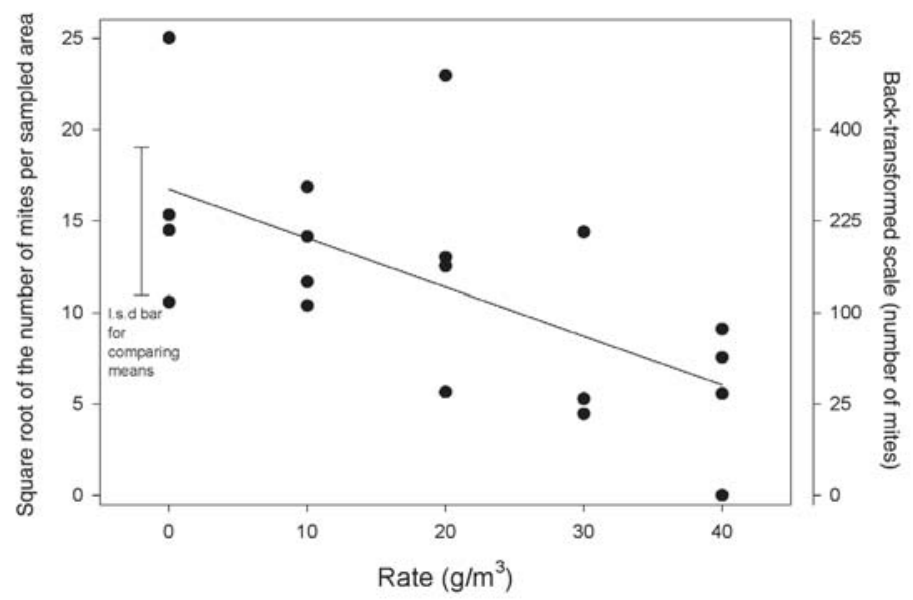

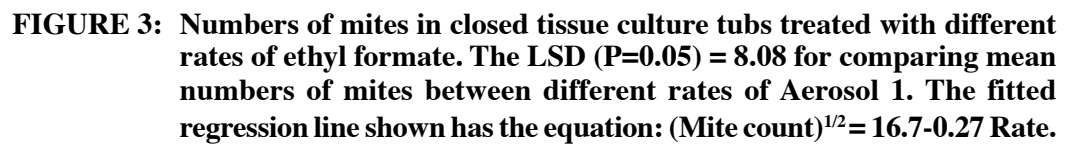

DISCUSSION

The practice of bringing plant material into a laboratory is the main reason for contamination of tissue culture rooms with mites or thrips. Normally, when tissue culture tubs become contaminated, the infested material is thrown out, but often there is only a limited supply of plants and this practice is costly for laboratories. When plant material that may contain mites is received for tissue culture, careful hygiene should be the first step in preventing mite and thrips infestation. Most other measures for preventing mite infestation are difficult to adapt to a tissue culture situation or may be hazardous to the health of those working with tissue culture material.

This work has shown that ethyl formate was effective in killing both mites and thrips in simulated and real tissue culture situations. This treatment would be applied to high value material only. Ethyl formate is a relatively safe aerosol treatment. The Food and Drug Administration of the USA reviewed the use of ethyl formate and concluded that there is no evidence to indicate that it is a hazard to the public when the chemical is used as a flavouring agent (Desmarchelier 1999).

Ethyl formate showed both a dose response and increased mortality over time, indicating that there is potential for further work to define optimum levels of this chemical for control of mites and thrips in tissue culture. Our experiments indicated that ethyl formate is not phytotoxic to begonia plantlets. However, it is phytotoxic to many cut flowers and ornamental species (Weller et al. 1995) so phytotoxicity potential should be further investigated prior to its use with other types of tissue-cultured plants. 


\section{ACKNOWLEDGEMENTS}

The authors would like to thank Hari Krishna for technical advice, and Brent Page, Zheng Zhang and Alby Marsh for technical assistance. BOC NZ Ltd supplied Insectigas, Pestigas and VAPORMATE ${ }^{\mathrm{TM}}$.

\section{REFERENCES}

Anon. 2003: Department of Primary Industries Queensland. Grain storage-psocid and mite pests. http://www.agric.wa.gov.au/ento/publications/fs0439.html (4/14/03).

Blake, J. 1988: Mites and thrips as bacterial and fungal vectors between plant tissue cultures. Acta Hort. 225: 163-166.

CABI Bioscience. 2002: Plant-tc-Monthly Archive. http://www.cabi-bioscience.org/ Htlm/guidelines.htm (27/08/02).

Desmarchelier, J.M. 1999: Ethyl formate and formic acid: occurrence and environment fate. Postharvest News and Information 10(1): $7 \mathrm{~N}-12 \mathrm{~N}$.

Kirk, D. 1997: Plant-tc-Monthly Archive. http://www.agro.agri.umn.edu/plant.listserv/ 1997/log 9701/msg00074.html (1/9/02)

van Epenhuijsen, C.W. 1995: A device for collecting accurate numbers of small insects. The Weta News Bulletin of the Entomological Society of New Zealand Inc. 18: 2526.

van Epenhuijsen, C.W.; Koolaard, J.P. 2004: Monitoring and controlling mould mites in tissue culture facilities. N.Z. Plant. Prot. 57: 196-201.

Weller, G.L.; van S. Graver, J.E.; Damcevski, K.A. 1995: Replacements for methyl bromide in quarantine treatments of cut flowers and ornamentals. In: Science and technology for the fresh food revolution. Australasian Postharvest Horticulture Conference, Melbourne. Pp. 367-372. 